\title{
A Model to Study Antioxidant Regulation of Endotoxemia-Modulated Neonatal Granulopoiesis and Granulocyte Apoptosis
}

\author{
KUENDER D. YANG, MEI-ZU CHEN, RU-JENG TENG, MING-YU YANG, HSIU-CHIN LIU, \\ RONG-FU CHEN, TE-YAO HSU, AND MEN-FANG SHAIO
}

\begin{abstract}
Chang Gung Children's Hospital at Kaohsiung [K.D.Y., M.-Z.C., M.-Y.Y., H.-C.L., R.F.C.], Department of Obstetrics [T.Y.H.], Chang Gung Memorial Hospital, Kaohsiung 833, Taiwan; Department of Pediatrics, National Taiwan University Hospital, Taipei 100, Taiwan [R.-J.T.]; and Department of Parasitology and Tropical Medicine, National Defense Medical Center, Taipei 100, Taiwan [M.-F.S]
\end{abstract}

\begin{abstract}
Neonates with septicemia tend to develop granulocytopenia, which may, in part, be due to septic mediators such as oxygen free radicals and tumor necrosis factor alpha (TNF- $\alpha$ ). Granulocytopenia may be caused by a decrease in granulocyte growth and/or an increase in granulocyte destruction. In the present study, we investigated antioxidant regulation of endotoxinmodulated neonatal granulopoiesis and granulocyte apoptosis. Using human umbilical cord blood (HUCB), we found that simulating endotoxemia in vitro elicited significant superoxide production within a few minutes. Endotoxin exposure suppressed colony-forming unit-granulocyte and monocyte formation in a dose-dependent fashion. Addition of antioxidants such as $\mathrm{N}$ acetyl-cysteine could reverse the endotoxin suppression of colony-forming unit-granulocyte and monocyte formation (13 \pm 5 versus $75 \pm 5$ colony-forming units $/ \mathrm{mL}$ ). Spontaneous in vitro granulocyte apoptosis in $6 \mathrm{~h}$, as reflected by phosphatidylserine expression on the cell surface, was higher in granulocytes from HUCB than in those from adult blood $(10.8 \pm 1.0 \%$ versus 5.6 $\pm 1.2 \%$ ). The addition of endotoxin or IL- 8 to the cells in the in vitro model did not promote granulocyte apoptosis, but TNF- $\alpha$,
\end{abstract}

\section{ABSTRACT}

a major mediator of the effects of endotoxin, significantly induced granulocyte apoptosis in HUCB (control versus TNF- $\alpha$ : $8.9 \pm 1.2 \%$ versus $35.9 \pm 2.9 \%$ ). Addition of the antioxidant $\mathrm{N}$-acetyl-cysteine effectively blocked TNF- $\alpha$-induced granulocyte apoptosis as demonstrated by DNA fragmentation. Results from these studies indicate that oxygen radicals are directly involved in endotoxin suppression of granulopoiesis, and indirectly promote granulocyte apoptosis, presumably through TNF$\alpha$-mediated action. Thus, under certain conditions, modulation of oxygen radical production in the blood may benefit neonates with granulocytopenia. (Pediatr Res 48: 829-834, 2000)
HUCB, human umbilical cord blood
CFU-GM, colony-forming units-granulocyte and monocyte
LPS, lipopolysaccharide
NAC, N-acetyl-cysteine
PS, phosphatidylserine
SOD, superoxide dismutase
TNF- $\alpha$, tumor necrosis factor alpha

Phagocytes, and especially granulocytes, act as an important first line of defense against bacteria. Patients with bacterial sepsis tend to develop granulocytopenia. It is possible that septic mediators such as oxygen radicals and TNF- $\alpha$ may be implicated in the pathogenesis of the decrease in granulocytes $(1,2)$. Newborns, especially prematures, appear to be more susceptible to oxygen radical mediated diseases and have been reported to possess less antioxidant activity than adults (3). Neonates with sepsis are prone to develop granulocytopenia

Received January 13, 2000; accepted June 25, 2000.

Correspondence and reprint requests: Dr. Kuender D. Yang, Chang Gung Children's Hospital at Kaohsiung, Office of Vice Superintendents, 123 Ta-Pei Road, Niau-Sung, Kaohsiung 833, Taiwan.

This work was supported, in part, by grants NSC88-2314-B182-096 and NSC 89-2320B-182-007-M53 from the National Science Council, Taiwan. and this can be correlated with a poor outcome (4). It is uncertain whether sepsis-induced oxygen radicals can cause a decrease in granulocyte growth or promote an increase in granulocyte destruction in neonates. Others have demonstrated that an in vitro HUCB model is useful for assessing the effects of drugs and biochemicals on hematopoiesis $(5,6)$. Granulocyte apoptosis can also be assessed by the detection of early cell surface exposure of phosphatidylserine (PS) and late DNA fragmentation $(7,8)$. Employing this in vitro HUCB endotoxemia model, we sought to determine whether endotoxin elicited oxygen radicals in the HUCB and whether the oxygen radicals were involved in neonatal granulocyte growth and apoptosis.

Oxygen radicals such as superoxide $\left(\mathrm{O}_{2}^{-}\right)$are involved in the signaling for proliferation of smooth muscle cells (9) and slime 
mold differentiation (10). $\mathrm{H}_{2} \mathrm{O}_{2}$ has also been implicated in the induction of $\mathrm{NF} \varkappa \mathrm{B}$ translocation by oxidized LDL in monocytes $(11,12)$. In earlier work, we demonstrated that hydroxyl radicals $(\mathrm{OH} \cdot)$ but not $\mathrm{H}_{2} \mathrm{O}_{2}$ or superoxide is involved in phorbol ester-induced monocytic differentiation of HL-60 cells (13). In addition to influencing the growth and differentiation of myeloid cells, free radicals are also implicated in programmed cell death (14-16). Bauer et al. (14). have shown that oxygen radicals are involved in the transcriptional regulation of CD95 ligand (Fas ligand) expression and that antioxidants diminish functional expression of Fas ligand in the apoptotic process. Moreover, it has been suggested that antioxidants such as pyrrolidine dithiocarbamate (PDTC) and NAC might prevent apoptosis in lymphocytes $(15,16)$, neurons $(17)$, and vascular endothelial cells (18). Thus, it seems reasonable to propose that oxygen radicals and antioxidants in neonatal blood may modulate granulocyte growth and apoptosis during sepsis-induced endotoxemia.

\section{MATERIALS AND METHODS}

Study design. Using HUCB, we assessed the effects of endotoxin-induced oxygen radicals on the growth and apoptosis of granulocytes after approval by the hospital ethical committee. Growth of granulocytes was assessed by in vitro CFU-GM formation. Apoptosis of granulocytes was assessed by the early appearance of the cell surface apoptotic marker, PS expression, and the later apoptotic event, DNA fragmentation $(7,8)$. CFU-GM formation and granulocyte apoptosis were assessed in an in vitro model of endotoxemia in which endotoxin $(0.1-1000 \mathrm{ng} / \mathrm{mL})$ was incubated with HUCB. This model was modified from a report by Leglise et al. (5), who used it to study drug-related myelosuppression of hematopoiesis. We used whole blood instead of purified mononuclear cells because endotoxin (LPS) requires lipopolysaccharidebinding protein (LBS) in the plasma to trigger leukocyte activation (19). Whole blood to which endotoxin was not added was simultaneously studied as a negative control.

Reagents and stimuli. Ammonium chloride $\left(\mathrm{NH}_{4} \mathrm{Cl}\right)$ lysis buffer was used to deplete RBC from whole blood. Before flow cytometric analysis of PS expression on granulocytes, FITClabeled annexin- $\mathrm{V}$ binding to cell surface PS was determined in calcium chloride $(2.5 \mathrm{mM})$ and HEPES $(10 \mathrm{mM})$ containing normal saline at $\mathrm{pH}$ 7.4. Other agents and stimuli used were as follows: RPMI 1640 medium (GIBCO Inc., Grand Island, NY, U.S.A.), FCS (GIBCO Inc.), annexin-V FITC (PharMingen, San Diego, CA, U.S.A.), propidium iodide (PI) (Sigma Chemical Co. Inc., St. Louis, MO, U.S.A.), IL-8 (R\&D Systems Inc., Minneapolis, MN, U.S.A.), TNF- $\alpha$ (PharMingen), LPS (Sigma Chemical Co. Inc.), and the antioxidants SOD, catalase, and NAC (Sigma Chemical Co. Inc.).

Blood sampling and in vitro endotoxemia. Heparinized peripheral blood $(10 \mathrm{U} / \mathrm{mL})$ was obtained from healthy adult volunteers and also from the umbilical cords of normal spontaneous deliveries after informed consent was obtained. Various concentrations of LPS or TNF- $\alpha$ were added to samples of heparinized whole blood in vitro, to mimic endotoxemia. Furthermore, in some experiments we added antioxidants such as
NAC $(10 \mathrm{mM})$, SOD $(400 \mathrm{U} / \mathrm{mL})$, or catalase $(400 \mathrm{U} / \mathrm{mL})$ before the addition of endotoxin to investigate the effect of antioxidants upon CFU-GM formation and apoptosis of granulocytes.

Determination of oxygen radical production in the in vitro model of endotoxemia. Production of oxygen radicals was determined by lucigenin-mediated chemiluminescence as previously described (13). In brief, $1 \mathrm{~mL}$ of HUCB was incubated with various concentrations of endotoxin $(0,10,100$, or 1000 $\mathrm{ng} / \mathrm{mL})$ in the presence or absence of antioxidants. The mixture was placed in a luminometer (1251 LKB, Wallac Oy, Turku, Finland) and continuously monitored for lucigenin-mediated chemiluminescence for $60 \mathrm{~min}$. Results are presented as a plot of time versus chemiluminescence. In additional studies to confirm that the major oxygen radicals released in endotoxemia are superoxide $\left(\mathrm{O}_{2}^{-}\right)$, we used the SOD-inhibitable cytomchrome $c$ reduction assay to directly measure $\mathrm{O}_{2}{ }^{-}$production as previously described (20). In brief, blood leukocytes $\left(5 \times 10^{6}\right.$ cells $/ \mathrm{mL}$ ) were stimulated with different concentrations of LPS in the presence of cytomchrome $c(80 \mu \mathrm{M})$ with and without SOD $(200 \mathrm{U} / \mathrm{mL})$ for $60 \mathrm{~min}$. Results were measured with an ELISA reader at $\mathrm{OD}_{550}$, and a molar extinction coefficient for cytomchrome $c$ reduction $\left(2.11 \times 10^{4} \mathrm{M}^{-1} \mathrm{~cm}^{-1}\right)$ was calculated. The production of $\mathrm{O}_{2}^{-}$is presented as nmol/ $10^{6}$ cells $/ 60$ min after specific subtraction of the SOD inhibitable background (20).

Assessment of myeloid progenitor cell growth (CFU-GM). Mononuclear cells (MNC, $4 \times 10^{5}$ cells/well) harvested from whole blood with and without the addition of endotoxin in the presence or absence of antioxidants as indicated were analyzed by CFU-GM assay. The CFU-GM assay was performed using semisolid agar plates containing 0.4\% Agar Nobel (Difco, Sparks, MD, U.S.A.), and Iscove's medium supplemented with autologous plasma $20 \%$ (vol/vol), IL-3 $(50 \mathrm{ng} / \mathrm{mL})$, and GMCSF (10 ng/mL) for $14 \mathrm{~d}$ as previously described (21). The antioxidants used in the study included SOD, catalase, and NAC. Results were calculated from those colonies with more than 32 cells aggregating on the agar plates (21).

Determination of flow cytometric analysis of leukocyte apoptosis by analysis of cell surface PS expression. Annexin- $\mathrm{V}$, a $\mathrm{Ca}^{2+}$-dependant phospholipid-binding protein with a high affinity for PS is a sensitive probe for detecting apoptotic cells by flow cytometry when conjugated to FITC (22). Whole blood $(100 \mu \mathrm{L})$ treated with endotoxin, TNF- $\alpha$, and/or IL-8 as indicated above was washed twice in $\mathrm{Ca}^{2+}$-containing binding buffer and stained with annexin-V FITC $(10 \mu \mathrm{L})$ and propidium iodide ( $10 \mu \mathrm{L} ; 50 \mu \mathrm{g} / \mathrm{mL})$ for 10 min at room temperature in the dark. After staining, cells were fixed with $1 \%$ paraformaldehyde, followed by a $\mathrm{NH}_{4} \mathrm{Cl}$ lysing buffer depletion of RBC. The apoptotic leukocytes were finally analyzed by flow cytometry as determined by FITC-labeled PS staining fluorescence. Adjacent controls were run with blood cells stained with an irrelevant FITC-labeled control antibody.

Determination of granulocyte apoptosis by DNA fragmentation. Granulocytes isolated from whole blood with or without treatment with endotoxin or TNF- $\alpha$ were subjected to DNA extraction with $0.5 \%$ SDS lysing buffer followed by proteinase $\mathrm{K}$ digestion $(1 \mathrm{mg} / \mathrm{mL})$ of nuclear protein for $4 \mathrm{~h}$ at $60^{\circ} \mathrm{C}$, as 
previously described (23). Total DNA was harvested by the standard phenol-chloroform extraction procedure followed by alcohol precipitation (23). The DNA $(20 \mu \mathrm{g})$ was subjected to $1.5 \%$ agarose gel electrophoresis. The size characteristics of the DNA ladders were confirmed using a series of 100-bp DNA ladder markers.

Statistical analysis. Results of CFU-GM formation are expressed as the mean \pm SE. Granulocyte apoptosis is presented as the proportion (\%) of PS-positive cells as well as the degree of DNA fragmentation as determined by gel electrophoresis. The $t$ test was used to determine the significance of differences between population means; $p<0.05$ was taken as indicating statistical significance.

\section{RESULTS}

Endotoxemia induction of oxygen radical production. Studies were first performed to determine whether oxygen radicals were induced by the exposure of the HUCB to endotoxin. Various concentrations of endotoxin $(10-1000 \mathrm{ng} / \mathrm{mL})$ were added to HUCB to mimic endotoxemia. The production

(A)

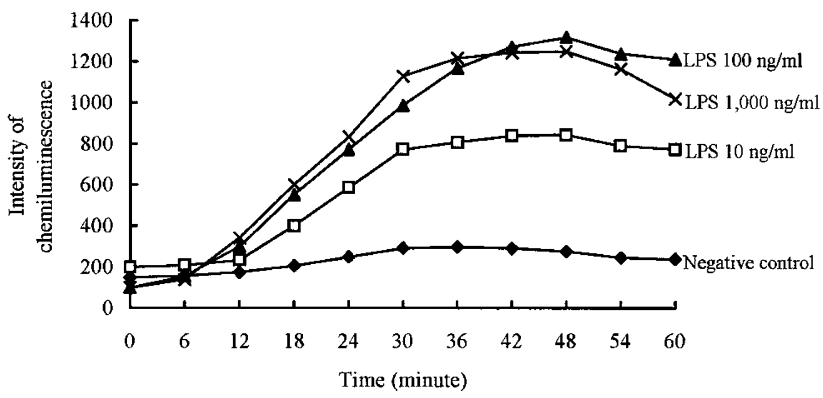

(B)

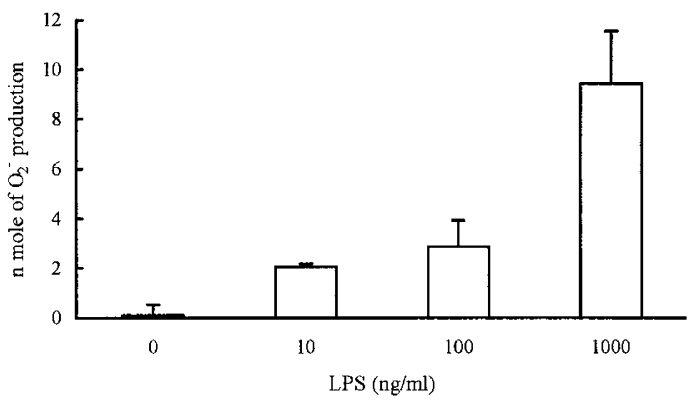

Figure 1. Oxygen radicals elicited in HUCB by endotoxin. HUCB $(1 \mathrm{~mL})$ was incubated with various concentrations of endotoxin (LPS: 0, 10, 100, 1000 $\mathrm{ng} / \mathrm{mL})$ in the presence of lucigenin $(0.1 \mathrm{mg} / \mathrm{mL})$. Lucigenin-mediated oxygen radical production was monitored in a luminometer (1251 LKB, Wallac Oy) for $60 \mathrm{~min}(A)$. Superoxide $\left(\mathrm{O}_{2}^{-}\right)$production was further confirmed by the direct measurement of $\mathrm{O}_{2}{ }^{-}\left(\mathrm{nmol} / 10^{6}\right.$ cells) by SOD-inhibitable cytomchrome $c$ reduction $(B)$. Results are presented as mean values calculated from three experiments with a total of six HUCB samples. of oxygen radicals in the in vitro endotoxemia was monitored by lucigenin-mediated chemiluminescence, and the superoxide production was assessed by SOD-inhibitable cytomchrome $c$ reduction assay. As shown in Figure 1A, we found that oxygen radicals were induced in a few minutes in a dose-dependent fashion, reaching a plateau when the endotoxin concentrations approached $100 \mathrm{ng} / \mathrm{mL}$. Superoxide production as determined by SOD-inhibitable cytomchrome $c$ reduction demonstrated that addition of different doses of endotoxin $(10,100,1000$ $\mathrm{ng} / \mathrm{mL}$ ) elicited superoxide production in a range of $2.1 \pm 0.1$ to $9.4 \pm 2.1 \mathrm{nmol} / 10^{6}$ cells in $60 \mathrm{~min}$ (Fig. $1 B$ ). In support of this being superoxide production, we also demonstrated that oxygen radical-triggered chemiluminescence was specifically blocked by addition of superoxide dismutase but not catalase (Fig. 2).

Endotoxemia suppression of CFU-GM formation. Mononuclear leukocytes (MNC) obtained from HUCB demonstrated CFU-GM formation up to $40 \pm 9 \mathrm{CFU} / 10^{6} \mathrm{MNC}$. In contrast, MNC obtained from adult peripheral blood gave rise to minimal CFU-GM formation $\left(2 \pm 1 \mathrm{CFU} / 10^{6}\right.$ cells $)$. This indicates that there were more myeloid precursors present in HUCB than in adult blood. Incubation of HUCB with endotoxin $(0,0.1,1$, 100 , and $1000 \mathrm{ng} / \mathrm{mL}$ ) for $2 \mathrm{~h}$ before harvesting $\mathrm{MNC}$ for the colony formation assay resulted in a dose-dependent suppression of CFU-GM formation ( $50 \pm 9$ versus $31 \pm 9,25 \pm 13$, $15 \pm 7$, and $15 \pm 3$ PFU/10 6 cells, respectively) (Fig. $3 A$ ).

Antioxidant reversal of endotoxemia-suppressed $C F U$-GM formation. Because endotoxin can induce superoxide production, as shown above, experiments were next performed to test whether endotoxin suppression of CFU-GM formation could be reversed by the addition of antioxidants. Results calculated from eight triplicate experiments showed that NAC and SOD could significantly reverse endotoxin suppression of CFU-GM formation $\left(75 \pm 5\right.$ and $62 \pm 9$ versus $13 \pm 5 \mathrm{CFU} / 10^{6} \mathrm{MNC}$, respectively) (Fig. 3B).

Granulocytes in the HUCB undergo spontaneous apoptosis. It has been reported that granulocytes have a short circulating transit time of about $6 \mathrm{~h}$ in the blood; patients with multiple transfusions may have an even shorter time of less than $1 \mathrm{~h}$ (24). The demise of blood granulocytes occurs primarily through apoptosis $(7,8)$. For these reasons, we further

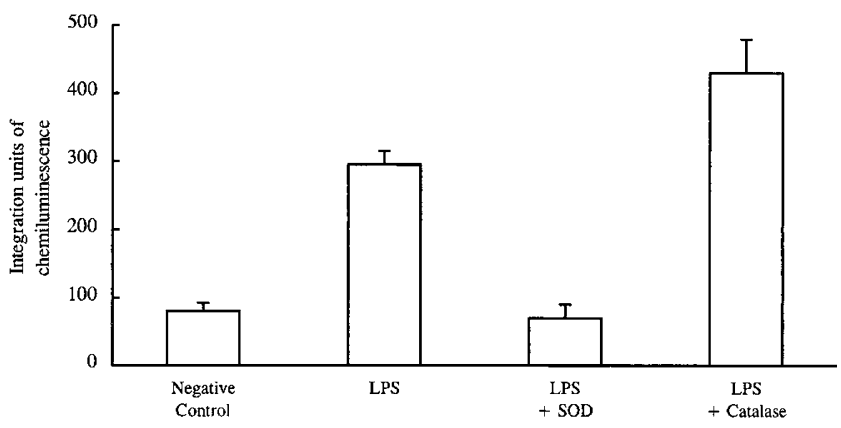

Figure 2. Antioxidant modulation of endotoxin-mediated oxygen radical production. HUCB ( $1 \mathrm{~mL}$ ) was incubated with and without endotoxin (LPS, $1 \mu \mathrm{g} / \mathrm{mL}$ ) in the presence of SOD or catalase $(400 \mathrm{U} / \mathrm{mL})$ before measurement of lucigeninmediated chemiluminescence for $60 \mathrm{~min}$. The integration results of the chemiluminescence assay under the area of the reaction curves are shown with mean $\pm \mathrm{SE}$ calculated from three experiments with a total of six HUCB samples. 
(A)

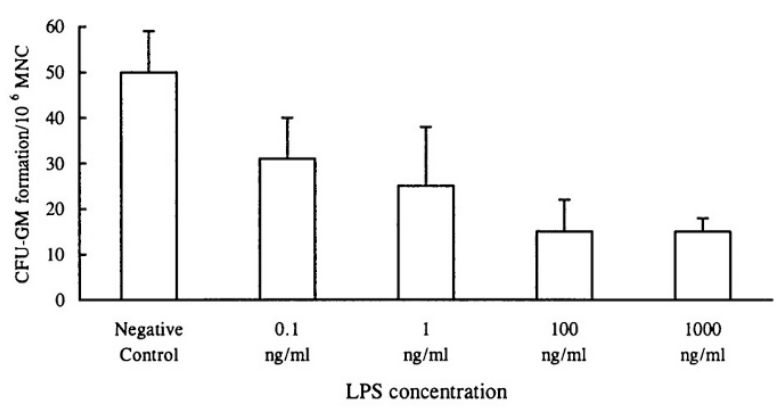

(B)

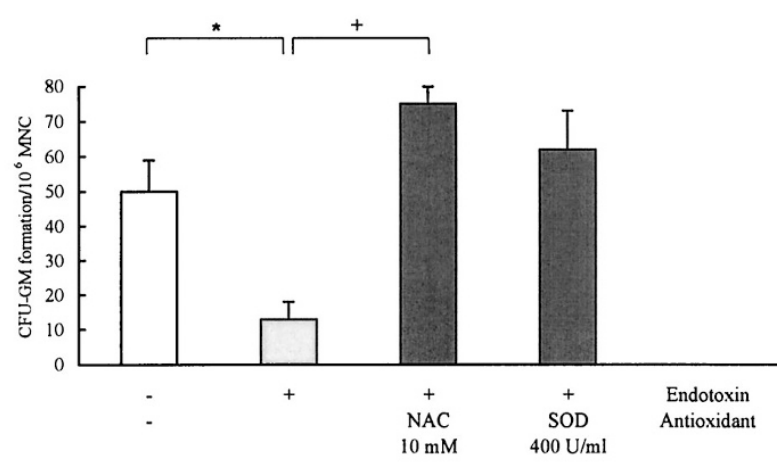

Figure 3. In vitro suppression of CFU-GM formation in HUCB by endotoxin $(A)$. HUCB $(5 \mathrm{~mL})$ was incubated with various concentrations of endotoxin (LPS: $0,0.1,1,100,1000 \mathrm{ng} / \mathrm{mL}$ ) for $2 \mathrm{~h}$. MNC harvested from endotoxintreated HUCB were subjected to CFU-GM formation assay. Antioxidant modulation of endotoxin suppression of CFU-GM formation $(B)$. HUCB (5 $\mathrm{mL}$ ) was incubated with $1000 \mathrm{ng} / \mathrm{mL}$ of LPS for $2 \mathrm{~h}$ in the presence of NAC $(10 \mathrm{mM})$ or SOD $(400 \mathrm{U} / \mathrm{mL})$. MNC harvested from the antioxidant and endotoxin-treated HUCB were subjected to CFU-GM formation assay. Results shown are calculated from eight triplicate experiments. * indicates a significant difference $(p<0.05)$ and + indicates a significant difference $(p<0.01)$.

investigated spontaneous apoptosis of granulocytes. As demonstrated by gel electrophoresis of DNA fragments, we found that granulocytes from HUCB tended to have a higher apoptosis rate than those from adult blood after in vitro incubation for 6 h (Fig. 4). Similarly, there was higher spontaneous early apoptosis of granulocytes from HUCB than from adult blood as demonstrated by flow cytometric analysis of PS expression on the granulocyte cell surface $(5.6 \pm 1.2$ versus $10.8 \pm 1.0 \%$; $p$ $<0.05, n=11$ ) (Fig. 5).

Effects of endotoxemia on granulocyte apoptosis. To investigate apoptosis of blood granulocytes in the presence of endotoxin, we added exogenous endotoxin $(1 \mu \mathrm{g} / \mathrm{mL})$ to HUCB. We found that in vitro exposure of HUCB to endotoxin did not affect the apoptosis of blood granulocytes from HUCB as demonstrated by PS expression on the granulocytes. The granulocyte apoptosis rate in the blood incubated with endotoxin for $6 \mathrm{~h}$ was not different from that incubated without endotoxin $(12.1 \pm 2.7$ versus $8.9 \pm 1.2 \%)$ (Fig. $6 A)$. We next used TNF- $\alpha(50 \mathrm{ng} / \mathrm{mL})$, the major mediator of endotoxemia $(25,26)$, for studies. We found that granulocytes from HUCB were susceptible to TNF- $\alpha$-induced apoptosis $(8.9 \pm 1.2$ versus $35.9 \pm 2.9 ; p<0.01$; Fig. $6 A$ ). In studies with different

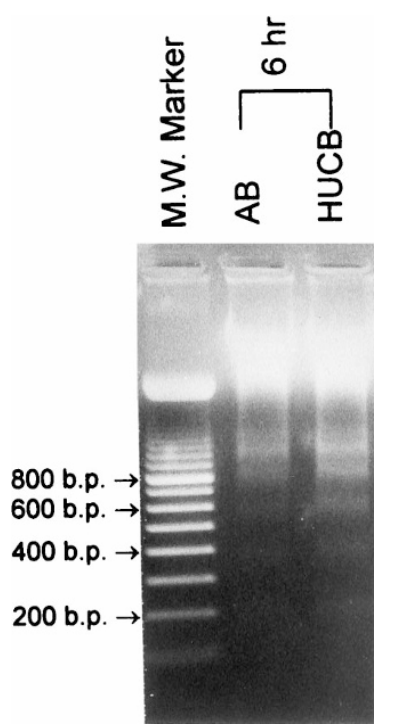

Figure 4. Spontaneous apoptosis of granulocytes in adult blood and HUCB as demonstrated by DNA fragmentation. Adult blood (AB) and HUCB $(5 \mathrm{~mL})$ were incubated at $37^{\circ} \mathrm{C}$ for $6 \mathrm{~h}$. Granulocytes in the blood were purified and subjected to DNA extraction by $0.5 \%$ SDS lying buffer (23). Extracted DNA was harvested using a phenol-chloroform separation technique and analyzed by electrophoresis in $1.5 \%$ agarose gel. The resultant band patterns were compared with a series of 100-bp DNA markers.

concentrations of TNF- $\alpha$, we found that the larger $(50 \mathrm{ng} / \mathrm{mL})$, but not smaller $(0.5 \mathrm{ng} / \mathrm{mL})$, TNF- $\alpha$ concentration could effectively induce neonatal granulocyte apoptosis (Fig. 6B). IL-8 $(10 \mathrm{ng} / \mathrm{mL})$ alone, or in combination with TNF- $\alpha$ at various concentrations $(0.5,5$, and $50 \mathrm{ng} / \mathrm{mL})$ had a limited effect on neonatal granulocyte apoptosis (Fig. 6B). As demonstrated by the late apoptotic marker-DNA fragmentation-we found that endotoxin $(1 \mu \mathrm{g} / \mathrm{mL})$ failed to promote in vitro neonatal granulocyte apoptosis. In contrast, TNF- $\alpha(50 \mathrm{ng} / \mathrm{mL})$ did promote this response (Fig. 7). NAC $(10 \mathrm{mM})$, which was shown to reverse endotoxin suppression of CFU-GM formation in HUCB, blocked TNF- $\alpha$-mediated granulocyte apoptosis in HUCB (Fig. 7).

\section{DISCUSSION}

Granulocytopenia may have a variety of etiologies. Our approach to explore whether oxygen radicals are involved in endotoxin-mediated neonatal granulocytopenia is based on the HUCB model from which granulopoiesis and granulocyte apoptosis may be monitored in vitro. Using a similar model, Leglise et al. (5). showed that CFU-GM formation from HUCB provided a useful model for the evaluation of myelosuppression by xenobiotics, which was comparable to in vivo situations. In our study, we found that endotoxin-induced superoxide was directly involved in modulation of granulopoiesis. Although endotoxin alone did not promote granulocyte apoptosis, the endotoxin mediator, TNF- $\alpha$, promoted the granulocyte apoptosis. The fact that higher TNF- $\alpha$ concentrations $(5-50 \mathrm{ng} / \mathrm{mL})$, but not endotoxin itself or lower TNF- $\alpha$ concentrations $(0.5-5 \mathrm{ng} / \mathrm{mL})$, induced blood granulocyte apoptosis in our study may not be related to the actual in vivo sepsis, in which the blood TNF- $\alpha$ levels were lower $(0.05-0.13$ 
(A)
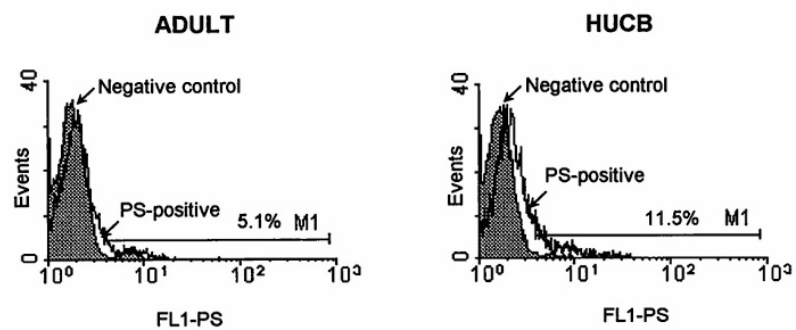

(B)

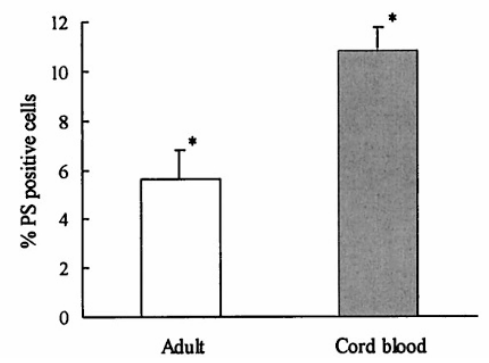

Figure 5. Spontaneous expression of PS on the granulocytes in adult blood and HUCB. (A) Granulocytes from HUCB showed a higher percentage of PS expression on the cell surface than those from adult blood in a representative flow cytometric analysis with FITC-labeled annexin-V staining. (B) Data (mean $\pm \mathrm{SE}$ ) calculated from the duplicate experiments of 11 blood samples from each group of HUCB and adults showed a significantly greater $(p<0.05)$ percentage of PS-positive granulocytes in HUCB than in adult blood.

$\mathrm{ng} / \mathrm{mL})(27)$ than the higher concentrations $(0.5-50 \mathrm{ng} / \mathrm{mL})$ used in this study. It is, however, not excluded that a higher TNF- $\alpha$ level $(>0.5 \mathrm{ng} / \mathrm{mL})$, as might be present in infected or inflammatory tissues, could promote blood granulocyte apoptosis. Moreover, we found that TNF- $\alpha$-mediated granulocyte apoptosis was significantly inhibitable by certain antioxidants. These studies suggest that oxygen radical production by blood leukocytes may have a role in regulating not only granulopoiesis but also granulocyte apoptosis in neonatal septicemia.

In support of the hypothesis that certain species of oxygen radicals may be involved in myeloid cell growth and proliferation, Beckman et al. (28) first reported that oxygen radicals act as a signal to induce erythroleukemic cell differentiation. Studies with macrophages/monocytes also showed that $\mathrm{H}_{2} \mathrm{O}_{2}$ was involved in the regulation of osteoclast formation (29). We previously showed that $\mathrm{OH} \cdot$ but not $\mathrm{H}_{2} \mathrm{O}_{2}$ or superoxide was involved in the phorbol ester-induced monocytic differentiation of HL-60 cells (13). We have further demonstrated in this current study that superoxide was directly involved in the endotoxin suppression of normal granulopoiesis. Similarly, several lines of evidence have suggested that antioxidants such as NAC can rescue lymphocytes, endothelial cells, and neuronal cells (15-18) from apoptosis, indicating reversal of the cell apoptosis by antioxidants. Blood granulocytes, which are critically involved in surveillance for bacterial infections, tend to have a short circulating transit time of about $6 \mathrm{~h}$. Regimens for
(A)

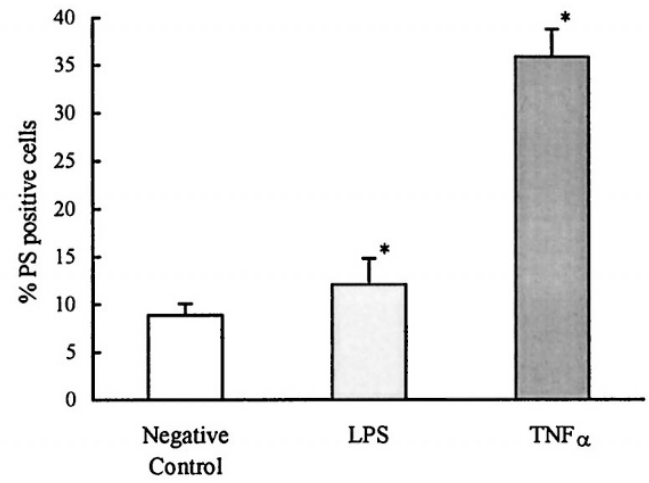

(B)

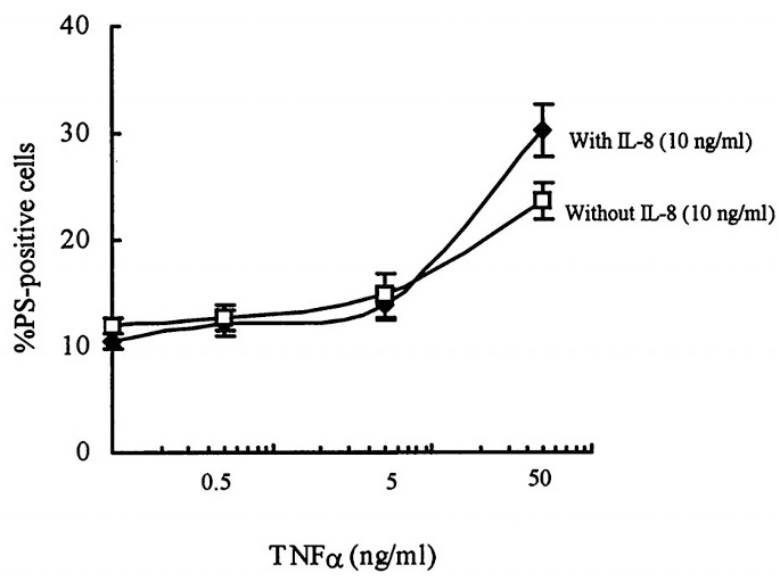

Figure 6. (A) TNF- $\alpha$ but not endotoxin (LPS) promoted granulocyte apoptosis. HUCB $(5 \mathrm{~mL})$ were incubated with and without LPS $(1.0 \mu \mathrm{g} / \mathrm{mL})$ or TNF- $\alpha(50$ $\mathrm{ng} / \mathrm{mL})$ for $6 \mathrm{~h}$ to mimic conditions of endotoxemia. The blood $(0.1 \mathrm{~mL})$ was then analyzed by flow cytometric analysis of PS expression on granulocytes with FITC-labeled annexin-V. (B) IL-8 enhancement of TNF- $\alpha$-mediated neonatal granulocyte apoptosis. IL-8 alone did not induce granulocyte apoptosis, but it did produce some enhancement of TNF- $\alpha$-mediated apoptosis when a higher concentration of TNF- $\alpha(50 \mathrm{ng} / \mathrm{mL})$ was studied. Results (mean $\pm \mathrm{SE})$ were calculated from 10 duplicate experiments $(*$ indicates $p<0.01$ ).

promoting granulocyte growth or minimizing granulocyte apoptosis with antioxidants may be useful in controlling septic granulocytopenia.

In this study, we demonstrated that NAC can reverse endotoxin suppression of granulopoiesis and block TNF- $\alpha$ mediated granulocyte apoptosis. Additional applications employing antioxidant modulation of granulocyte growth and apoptosis may be forthcoming after clarifying the four following complex questions: Do different leukocytes have varying susceptibilities to apoptosis in response to oxygen radicals? Do different species of oxygen radicals have varied abilities to induce cell apoptosis? Do oxygen radicals from different leukocytes and different metabolic pathways have varied functions in cell activation and cell apoptosis? And, do different antioxidants have varied effects to prevent cell apoptosis? We found in this study, for example, that NAC resulted in better reversal of endotoxin suppression of CFU-GM formation than other antioxidants such as SOD. The explanation for the dif- 


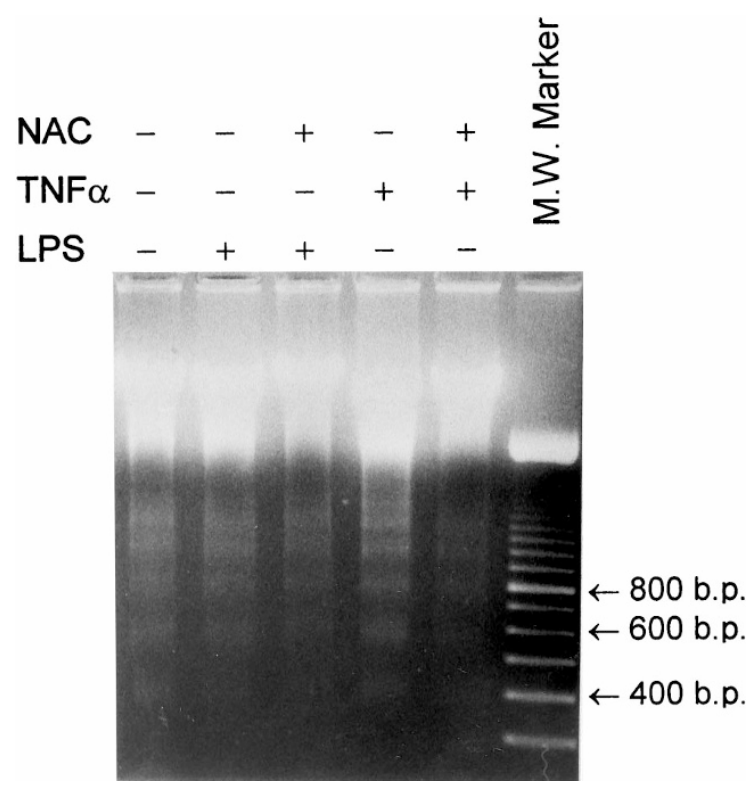

Figure 7. Effects of the antioxidant (NAC) on LPS and TNF- $\alpha$-induced granulocyte apoptosis. HUCB $(5 \mathrm{~mL})$ were incubated with and without LPS $(1.0 \mu \mathrm{g} / \mathrm{mL})$ or TNF- $\alpha(50 \mathrm{ng} / \mathrm{mL})$ in the presence and absence of NAC $(10$ $\mathrm{mM}$ ) at $37^{\circ} \mathrm{C}$ for $6 \mathrm{~h}$. Granulocytes in the blood were isolated and subjected to DNA extraction with a $0.5 \%$ SDS lysing buffer (23). Extracted DNA was harvested using a phenol-chloroform technique and analyzed by electrophoresis in $1.5 \%$ agarose gel. The resultant band pattern was compared with a series of 100-bp DNA markers.

ferent effects on the promotion of CFU-GM formation by NAC compared with SOD may relate to the observation that NAC is a membrane-permeable compound $(30,31)$, whereas SOD is not membrane permeable $(32,33)$.

In summary, we showed that simulating endotoxemia in the HUCB elicited oxygen radicals, which was mainly superoxide. The oxygen radical production was directly involved in the endotoxin suppression of CFU-GM formation from $\mathrm{HUCB}$ because the suppression could be reversed by the addition of antioxidants such as NAC and SOD. Endotoxin alone did not promote apoptosis of blood granulocytes; whereas the endotoxin-inducible mediator, TNF- $\alpha$, could induce NACinhibitable granulocyte apoptosis. A better understanding of the oxidant and antioxidant modulation of neonatal granulocyte growth and apoptosis may lead to the reversal of neonatal granulocytopenia by antioxidants in the future.

Acknowledgment. The authors thank the nursery staff in Chang Gung Memorial Hospital at Kaohsiung for their help in collecting umbilical cord bloods for studies. We also thank Dr. Hans D. Ochs and Dr. Harry R. Hill for their helpful review of the manuscript.

\section{REFERENCES}

1. Olson NC, Grizzle MK, Anderson DL 1987 Effect of polyethylene glycol-superoxide dismutase and catalase on endotoxemia in pigs. J Appl Physiol 63:1526-1532

2. Steinshamn S, Bemelmans MH, Buurman WA, Waage A 1995 Granulocytopenia reduces release of soluble TNF receptor 75 in endotoxin-stimulated mice: a possible mechanism of enhanced TNF activity. Cytokine 7:50-56

3. Saugstad OD 1990 Oxygen toxicity in the neonatal period. Acta Paediatr Scand 79:881-892

4. Wolach B 1997 Neonatal sepsis: pathogenesis and supportive therapy. Semin Perinatol 21:28-38
5. Leglise MC, Darodes de Tailly P, Vignot JL, Le Bot MA, Le Roux AM, Riche C 1996 A cellular model for drug interactions on hematopoiesis: the use of human umbilical cord blood progenitors as a mode for the study of drug-related myelosuppression of normal hematopoiesis. Cell Biol Toxicol 12:39-53

6. Kogler G, Callejas J, Sorg RV, Fischer J, Migliaccio AR, Wernet P 1998 The effect of different thawing methods, growth factor combinations and media on the ex vivo expansion of umbilical cord blood primitive and committed progenitors. Bone Marrow Transplant 21:233-241

7. Peters R, Leyvraz S, Perey L 1998 Apoptotic regulation in primitive hematopoietic precursors. Blood 92:2041-2052

8. Hiroi M, Tajima M, Shimojima T, Kashimata M, Miyata T, Sakagami H 1998 Re-evaluation of the culture condition of polymorphonuclear cells for the study of apoptosis induction. Anticancer Res 18:1813-1818

9. Lee SL, Wang WW, Fanburg BL 1998 Superoxide as an intermediate signal for serotonin-induced mitogenesis. Free Radic Biol Med 24:885-888

10. Allen RG, Balin AK, Reimer RJ, Sohal RS, Nations C 1998 Superoxide dismutase induces differentiation in microplasmodia of the slime mold Physarum polycephalum. Arch Biochem Biophys 261:205-211

11. Brand K, Eisele T, Kreusel U, Page M, Page S, Hass M, Gerling A, Kaltschmidt C, Neumann FJ, Mackman N, Baeurele PA, Walli AK, Neumeier D 1997 Dysregulation of monocytic nuclear factor-kappa B by oxidized low-density lipoprotein. Arterioscler Thromb Vasc Biol 17:1901-1909

12. Strack PR, Waxman L, Fagan JM 1996 Activation of the multicatalytic endopeptidase by oxidants. Effects on enzyme structure. Biochemistry 25:7142-7149

13. Yang KD, Shaio MF 1994 Hydroxyl radical as an early signal involved in phorbol ester-induced monocytic differentiation of HL60 cells. Biochem Biophys Res Commun 200:1650-1657

14. Bauer MKA, Vogt M, Los M, Siegel J, Wesselborg S, Schulze-Osthoff K 1998 Role of reactive oxygen intermediates in activation-induced CD95 (APO-1/Fas) ligand expression. J Biol Chem 273:8048-8055

15. Hockenbery DM, Oltvai ZN, Yin XM, Milliman CL, Korsmeyer SJ 1993 Bcl-2 function is an antioxidant pathway to prevent apoptosis. Cell 75:241-251

16. Sandstrom PA, Mannie MD, Buttke TM 1994 Inhibition of activation-induced death in $\mathrm{T}$ cell hybridomas by Thiol antioxidants: oxidative stress as a mediator of apoptosis. J Leukoc Biol 55:221-226

17. Kane DJ, Sarsfian TA, Anton R, Hahn H, Gralla EB, Valentine JS, Ord T, Bredesen DE 1993 Bcl-2 inhibition of neural death: decreased generation of reactive oxygen species. Science 262:1274-1277

18. Abello PA, Fidler SA, Bulkley GB, Buchman TG 1994 Antioxidants modulate induction of programmed endothelial cell death (apoptosis) by endotoxin. Arch Surg 129:134-140

19. Shapira L, Champagne C, Gordon B, Amar S, Van Dyke TE 1995 Lipopolysaccharide priming of superoxide release by human neutrophils: role of membrane CD14 and serum LPS binding protein. Inflammation 19:289-295

20. Yang KD, Shaio MF, Augustine NH, Hill HR 1994 Effects of fibronectin on phagocyte activation: implications in respiratory burst and actin polymerization. J Cell Physiol 158:347-353

21. Yang KD, Chao CY, Shaio MF 1998 Pentoxifylline synergizes with all-trans retinoic acid to induce differentiation of HL-60 myelocytic cells, but suppresses tRAaugmented clonal growth of normal CFU-GM. Acta Haematol 99:191-199

22. Susin SA, Zamzami N, Castedo M, Daugas E, Wang HG, Geley S, Fassy F, Reed JC, Kroemer G 1997 The central executioner of apoptosis: multiple connections between protease activation and mitochondria in Fas/APO-1 (CD95-) and ceramide-induced apoptosis. J Immunol 186:25-37

23. Marchetti P, Castedo M, Susin SA, Zamzami N, Hirsch T, Macho A, Haeffner A, Hirch F, Geuskens M, Kroemer G 1996 Mitochondrial permeability transition is a central coordinating event of apoptosis. J Exp Med 184:1155-1160

24. Dresch C, Najean Y, Bauchet J 1975 Kinetic studies of 51Cr and DF32P labelled granulocytes. Br J Haematol 29:67-80

25. Camus G, Poortmans J, Nys M, Deby-Dupont G, Duchateau J, Deby C, Lamy M 1997 Mild endotoxemia and the inflammatory response induced by a marathon race. Clin Sci 92:415-422

26. Berger D, Boelke E, Stanescu A, Buttenschoen K, Vasilescu C, Seidelmann M, Beger HG 1995 Endotoxemia and mediator release during colonoscopy. Endoscopy 27:671-675

27. de Werra I, Jaccard C, Corradin SB, Chiolero R, Yersin B, Gallati H, Assicot M, Bohuon C, Baumgartner JD, Galuser MP, Heumann D 1997 Cytokines, nitrite/nitrate, soluble tumor necrosis factor receptors, and procalcitonin concentrations: comparisons in patients with septic shock, cardiogenic shock, and bacterial pneumonia. Crit Care Med 25:607-613

28. Beckman BS, Balin AK, Allen RG 1989 Superoxide dismutase induces differentiation of Friend erythroleukemia cells. J Cell Physiol 139:370-376

29. Suda N, Morita I, Kuroda T, Murota S 1993 Participation of oxidative stress in the process of osteoclast differentiation. Biochim Biophys Acta 1157:318-323

30. Mazor D, Golan E, Philip V, Katz M, Jafe A, Ben-Zvi Z, Meyerstein N 1996 Red blood cell permeability to thio compounds following oxidative stress. Eur J Haematol 57:241-246

31. Abello PA, Fidler SA, Buchman TG 1994 Thio reducing agents modulate induced apoptosis in porcine endothelial cells. Shock 2:79-83

32. Schnackenberg CG, Welch WJ, Wilcox CS 1998 Normalization of blood pressure and renal vascular resistance in SHR with a membrane-permeable superoxide dismutase mimetic: role of nitric oxide. Hypertension 32:59-64

33. Mitchell JB, DeGraff W, Kaufman D, Krishna MC, Samuni A, Finkelstein E, Ahn MS, Hahn SM, Gamson J, Russo A 1991 Inhibition of oxygen-dependent radiationinduced damage by the nitroxide superoxide dismutase mimic, tempol. Arch Biochem Biophys 289:62-70 